\title{
DSP Based Monitoring and Controlling of DC Motor Using DSpace
}

\author{
${ }^{1}$ Mohammed Qasim Taha, ${ }^{2}$ Zaid H. Ali and ${ }^{3}$ Amer T. Saeed \\ ${ }^{1}$ Department of Biophysics, College of Applied Sciences, Hit, University of Anbar, Iraq \\ ${ }^{2}$ Technical Institute of Hawija, Department of Electrical Techniques, \\ Northern Technical University, Mosul, Iraq \\ ${ }^{3}$ College of Petroleum and Minerals Engineering, Tikrit University, Tikrit, Iraq
}

\begin{abstract}
In this research, Four-Quadrant DC Motor (FQDCM) operation is managed by determining alternating referenced speed command to a DC motor with a fixed ramp. The proposed speed controller is utilized to trace the instantaneous reference speed. A Simulink Model of the system has been built to match the hardware connections for the motor and DSpace equipment which interfaces the MATLAB Simulink with the motor monitoring probes. The operator DC-motor is coupled to the FQDCM. Also, current, terminal voltage and speed-torque relation equations are modeled using MATLAB code to regulate the experimental parts and extract the instantons values to be used in the analysis to observe the motor and control it under torque-control. This study will also address the monitoring of the speed controlled as well as torque-controlled motors to monitor and analyze the motor performance under the influence of stepped changing torque.
\end{abstract}

Key words: DSP, DC motor, Simulink, FQDCM, speed regulation, voltage regulation

\section{INTRODUCTION}

The research is designed to control a four-quadrant speed control system for a DC motor and set a new experimental perspective of machine controlling studied in engineering and technical schools and colleges in Iraq. The four-quadrant mode is so, named for the quadrants labeled as clockwise, counter clockwise, clockwise forward brake and reverse brake. This kind of machine also has a speed control feature. The DC motor operating in four-quadrant mode is very suitable for machines industry, since, they can be utilized in complex motions when $r$ equired because they can rotate in both clockwise and counterclockwise. Also, they research in braking mode immediate bi-directionally (Ajmera and Sankeshwari, 2013). In the practical scenarios, the motors in most cases are needed to stop immediately. Thus, the proposed controlling system is very handy due to the reverse brake and forward brake features. Therefore, instantaneous brakes in both directions can be applied. This occurs by reversing the voltage source across the terminals of operating motor for short time interval (Singh and Kosti, 2015). Furthermore, speed control of FQDCM is currently accomplished with other PWM converter topologies using simple microcontrollers (Taha and Lpizra, 2016). In this research work, the constant torque MATLAB Simulink Model for FQDCM is depicted in Fig. 1-3. The computer DSpace and Control-Desk programs and layouts simulations for DC motors have been built. Figure 1 illustrates MATLAB Simulink Model of the FQDCM monitoring system. Besides, the hardware of the DSP system connections is illustrated in Fig. 2. To keep FQDCM inertia known it has been coupled mechanically with conventional DC-motor (Ruzewski and Sobolewski, 2013). The speed-torque relationship Eq. 1-4 are as follows (Fig. 2a, b):

$$
\begin{gathered}
I_{a}=\frac{v_{a}-E_{b}}{R_{a}} \\
E_{b}=K_{e} \cdot W_{m} \\
T_{e m}=K_{T} I_{a} \\
K_{T}=K_{E}
\end{gathered}
$$

Where:

$\mathrm{V}_{\mathrm{a}}=$ Motor applied voltage

$\mathrm{I}_{\mathrm{a}}=$ The supplied current

$\mathrm{W}_{\mathrm{m}}=$ The motor speed and finally

$\mathrm{T}_{\mathrm{em}}=$ The electromagnetic torque in the motor

Corresponding Author: Mohammed Qasim Taha, Department of Biophysics, College of Applied Sciences, Hit, University of Anbar, Iraq 


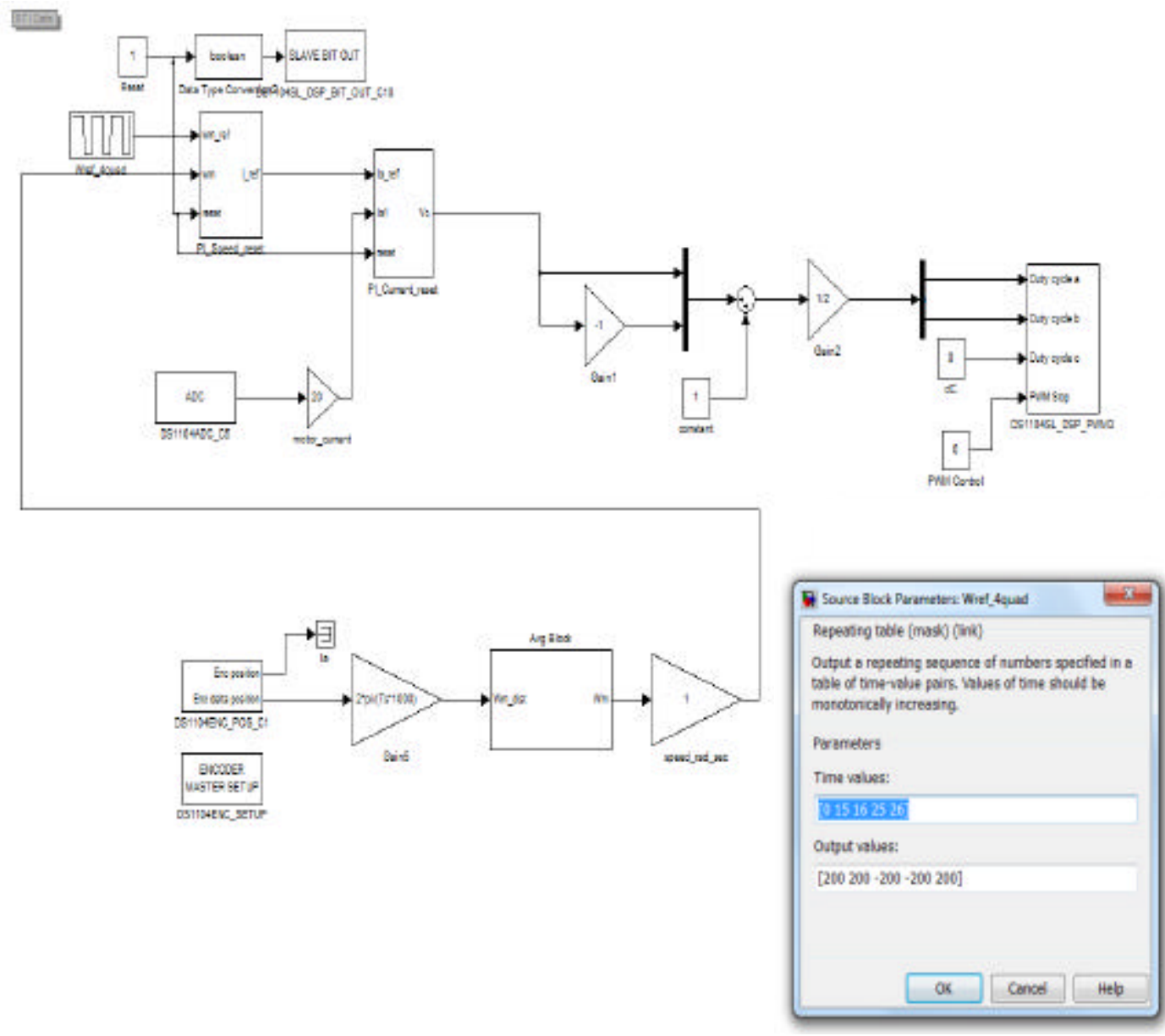

Fig. 1: FQDCM Simulink Model

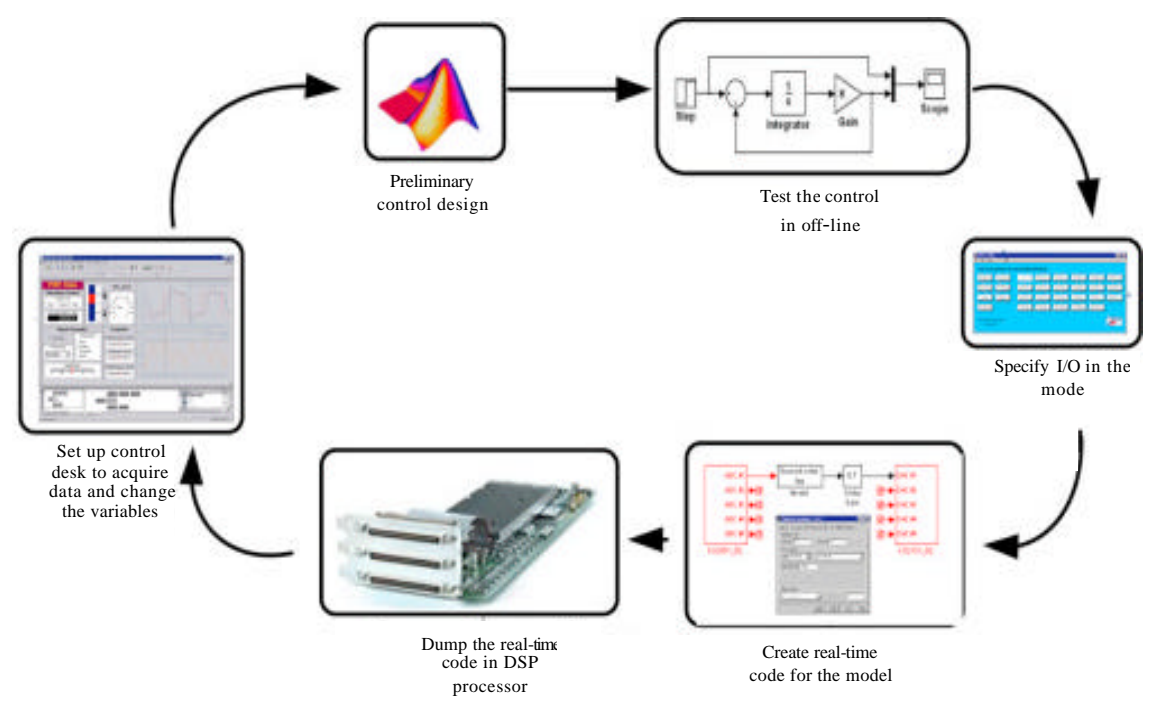

Fig. 2: Continue 


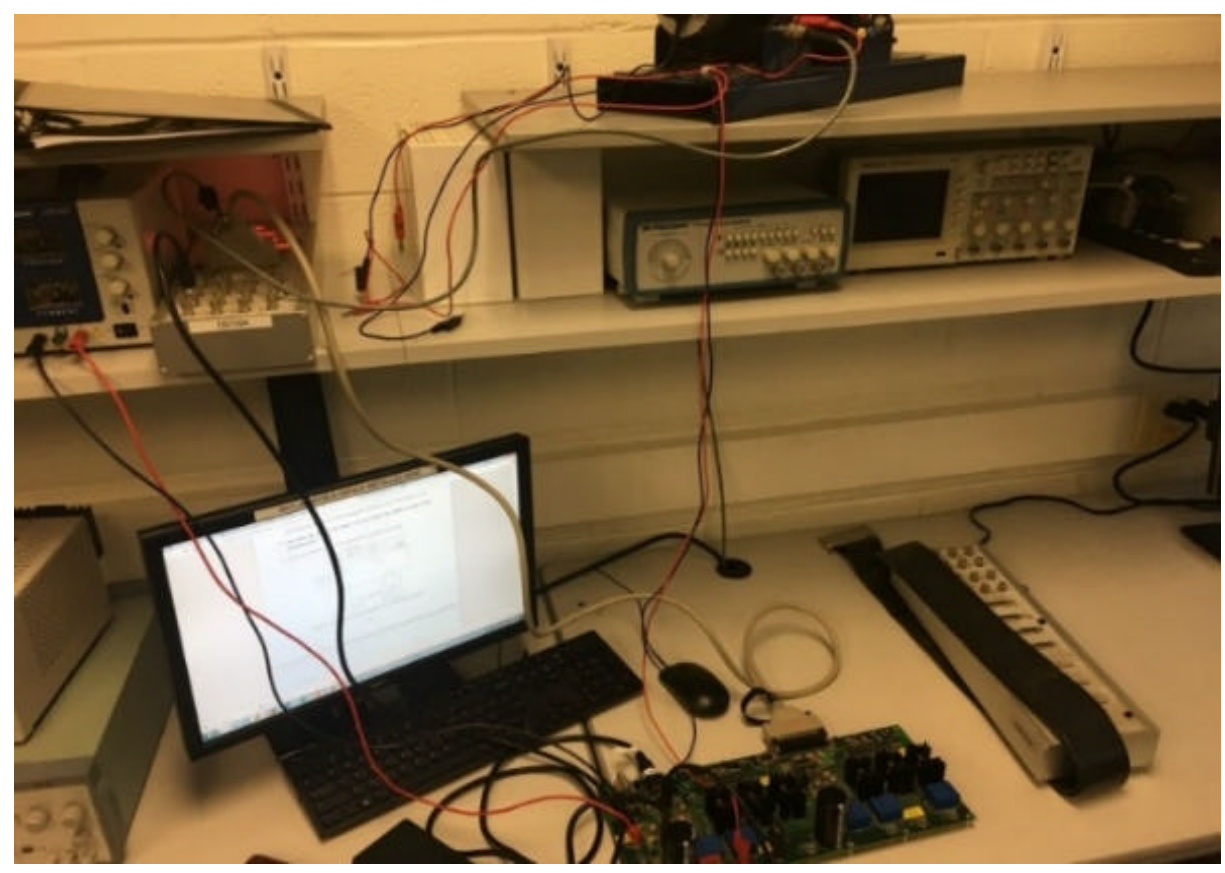

Fig. 2: a) College of Petroleum and Minerals Engineering and b) The connections of DSP-based DC motor controlling
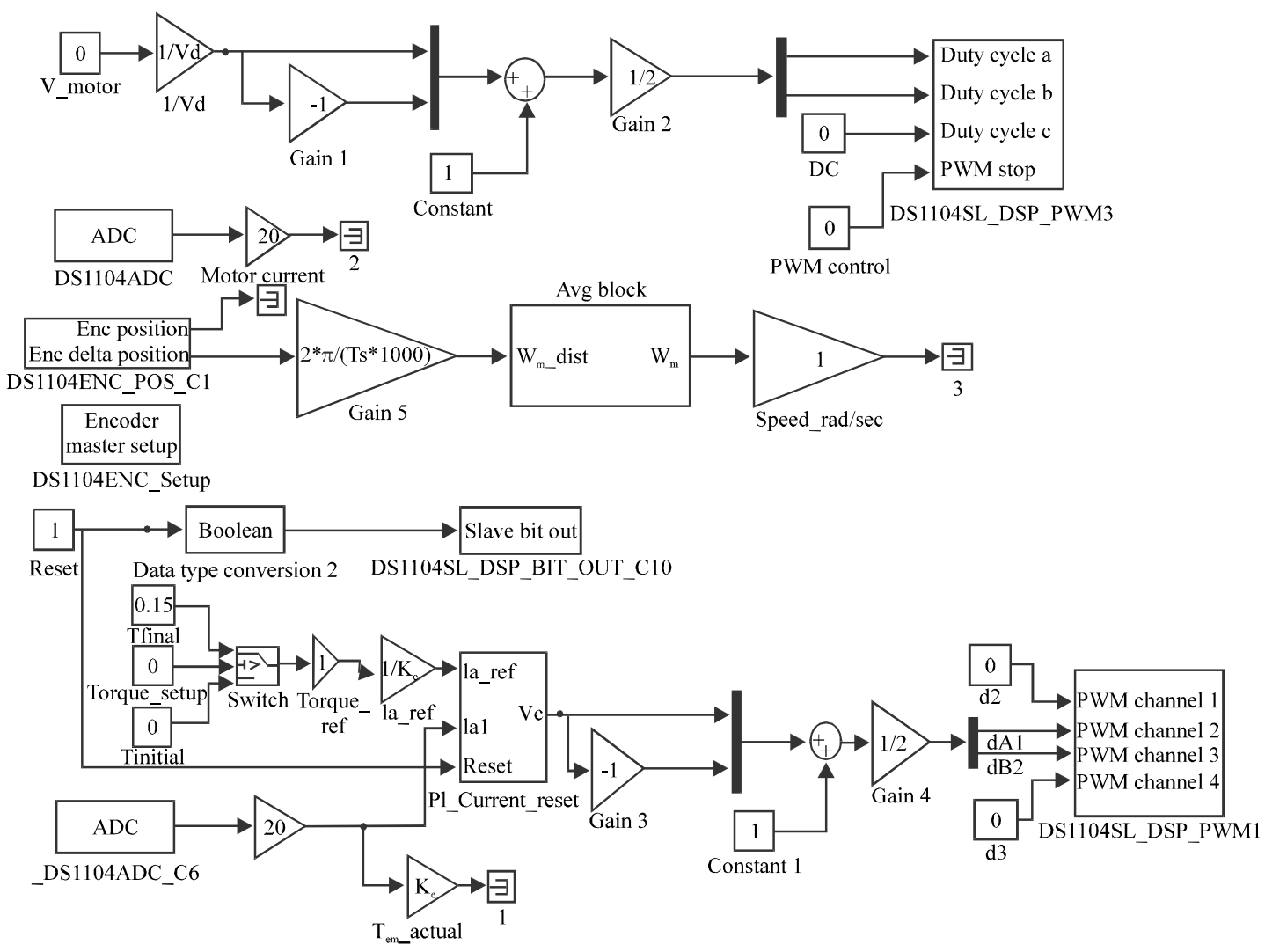

Fig. 3: FQDCM constant torque Simulink Model 


\section{MATERIALS AND METHODS}

Real-time implementation: The real-time representation of this experimental work has been built as shown in Fig. 1 the model was built for FQDCM speed control to extract a stepped signal with a range $(-200$ to +200$) \mathrm{rad} / \mathrm{sec}$ (Monje et al., 2010). The waveform for the reference speed has been fixed as well as the motor speed has been measured (Taha and Lpiza, 2016). Besides the coding and software setting the DSP based electric drive controlling system combined with 4 experimental devices which are: machines coupling mechanism, CP 1104 I/O board, power electronic drive board and DS1104 R\&D controlling board. Also, MATLAB Simulink and control desk software programs as shown in Fig. $2 a, b$.

DC motor speed control has been demonstrated in this experiment to illustrate the function of the components above. A motor coupling system consists of a generator and motor which needs to be controlled and then coupled together (Moreno, 2012a, b). Also, to sense the motor speed, encoder fixed on the FQDCM is used. The voltage is controlled by a PWM power electronic converter.

\section{RESULTS AND DISCUSSION}

\section{DC motor under torque control}

Constant load modeling: The modeling constant torque Simulink for FQDCM is illustrated in Fig. 3. The MATLAB code shown below is built and suitable values to the
PI current controller has been assigned. The values of the input voltage $\left(V_{d}=42 \mathrm{~V}\right)$ and torque $\left(T_{s}=1 \mathrm{e}-4 \mathrm{Nm}\right)$ has been monitored and entered at the command prompt of MATLAB Simulation.

The model also has been built in DSpace control desk programs as shown in Fig. 4 and the connections are shown in Fig. 5. The FQDCM constant applied voltage equal $12 \mathrm{~V}$. It is clear from the results in Fig. 4 that the speed of the motor is different when the range of load torque changes from $(0.0-0.15) \mathrm{Nm}$. Theoretically, the speed value estimation $(\mathrm{rad} / \mathrm{sec})$ at no load is calculated:

$$
\mathrm{w}_{\mathrm{m}}=\frac{\mathrm{v}_{\mathrm{a}}}{\mathrm{K}_{\mathrm{e}}}=\frac{12}{0.0924}=129.87 \mathrm{rad} / \mathrm{sec}
$$

But when the motor has loaded the estimation of the speed value in $\mathrm{rad} / \mathrm{sec}$ :

$$
\begin{gathered}
v_{a}=E_{a}+I_{a} * R_{a}, I_{a}=\frac{T_{e m}}{K_{T}} \\
I_{a}=\frac{0.15}{0.0924}=1.623 \mathrm{~A}
\end{gathered}
$$

$$
\mathrm{W}_{\mathrm{m}}=\frac{\left[\mathrm{v}_{\mathrm{a}}-\mathrm{I}_{\mathrm{a}}{ }^{*} \mathrm{R}_{\mathrm{a}}\right]}{\mathrm{K}_{\mathrm{e}}}=\frac{\left[12-1.623^{*} 0.6253\right]}{0.0924}=118.886 \mathrm{rad} / \mathrm{sec}
$$

The net power when the motor is not loaded:

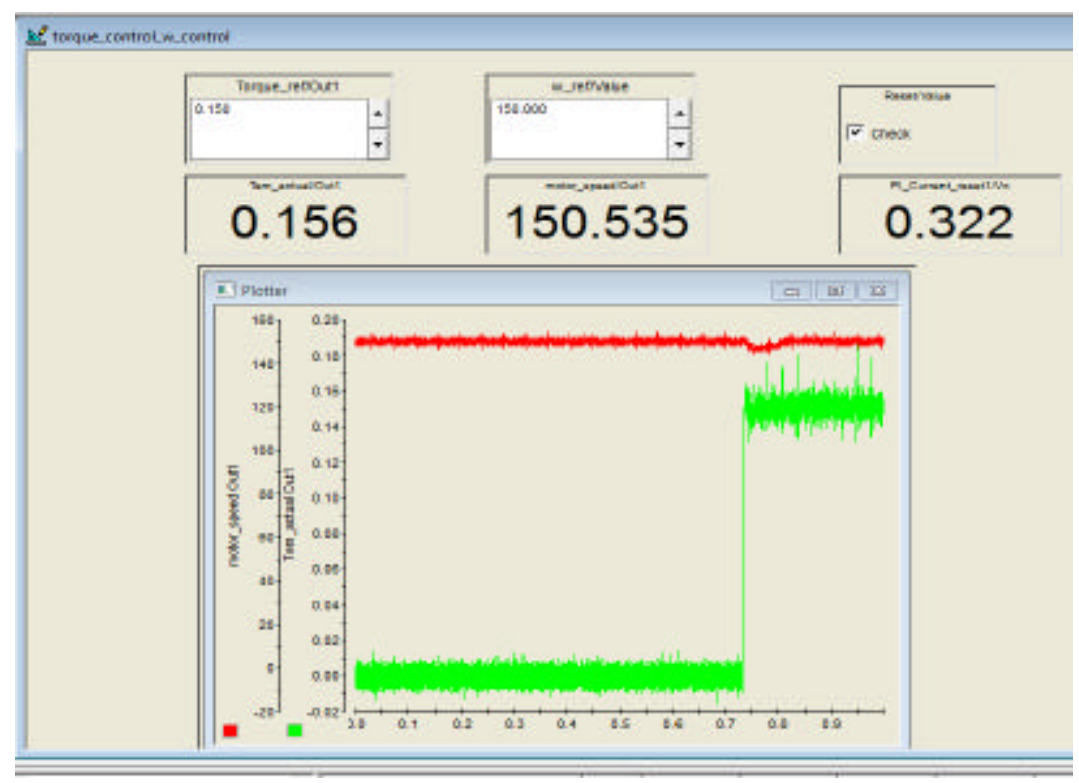

Fig. 4: FQDCM DSpace control desk layout for constant torque 


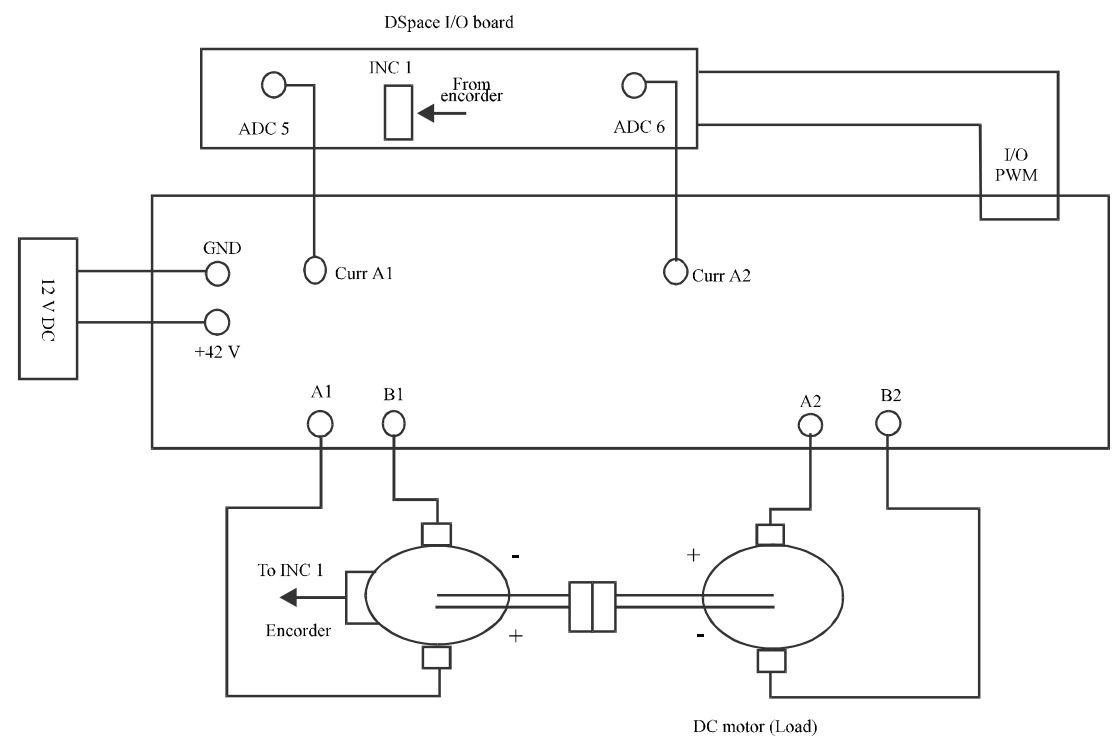

Fig. 5: Constant torque connections of FQDCM

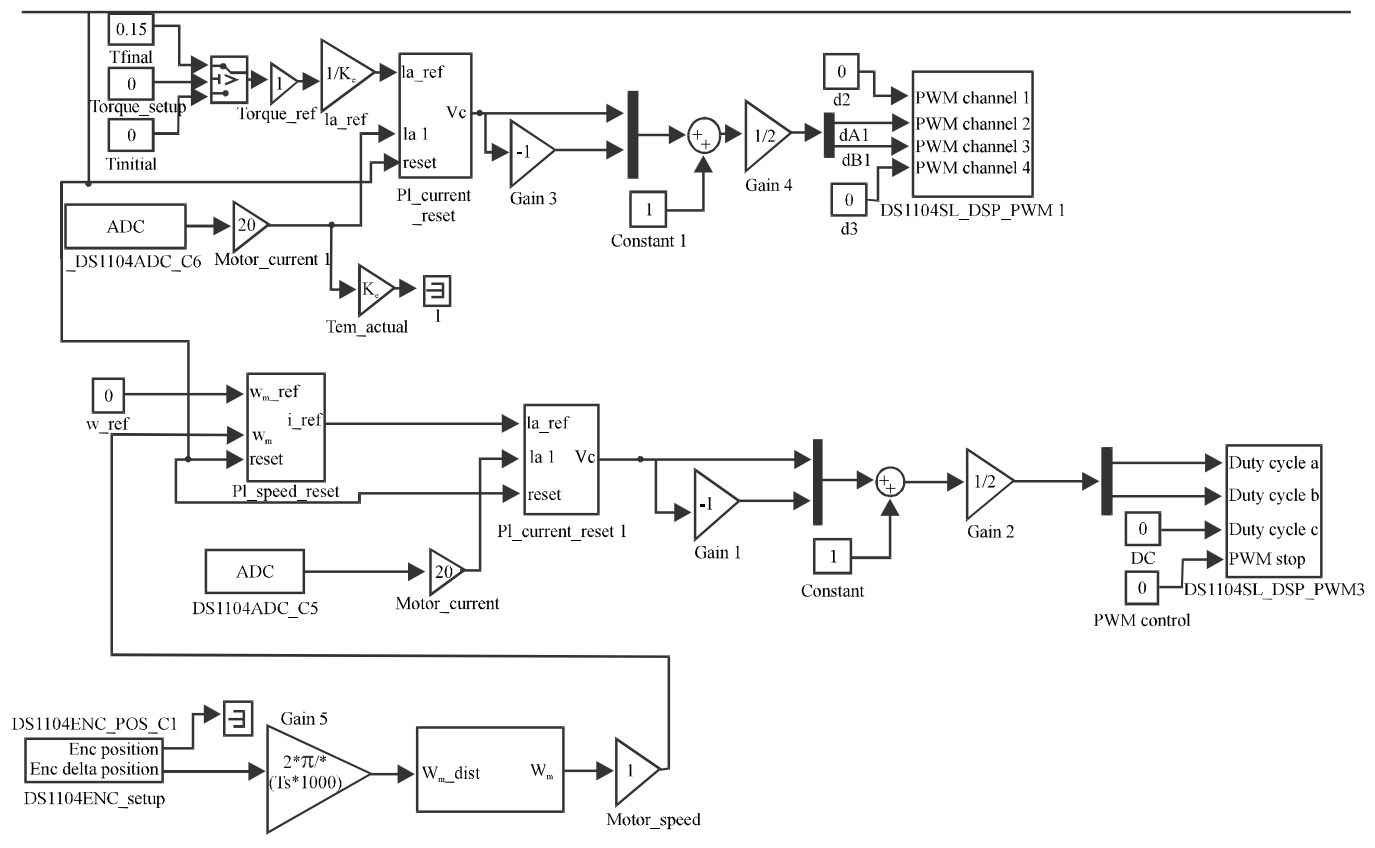

Fig. 6: Modeling of crane load for FQDCM

$$
\mathrm{p}_{\mathrm{e}}=\mathrm{p}_{\mathrm{m}}=0
$$

However, after applying the load the net power is calculated:

$$
\mathrm{p}_{\mathrm{e}}=\mathrm{p}_{\mathrm{m}}=\mathrm{w}_{\mathrm{m}}{ }^{*} \mathrm{~T}_{\mathrm{em}}=0.15^{*} 188.886=17.83 \mathrm{~W}
$$

The modeling of a crane load: This part will be to retain the load torque in the same direction with reversed speed. The crane mode is applied to change and reduce the

heavy loads. The Simulink Model is built as shown the in Fig. 6. The torque and speed response are shown in Fig. 7. To rotate the motor in reverse direction by supplying a fixed voltage $(-12 \mathrm{~V})$ to the FQDCM (Taha and Lpiza, 2016; Rojas-Moreno et al., 2016). It is obvious from the results in Fig. 7, the speed is changing when the torque change (Taha and Lpiza, 2016). The estimation of the speed value in $\mathrm{rad} / \mathrm{sec}$ at no load when the voltage (-12) is calculated as: 


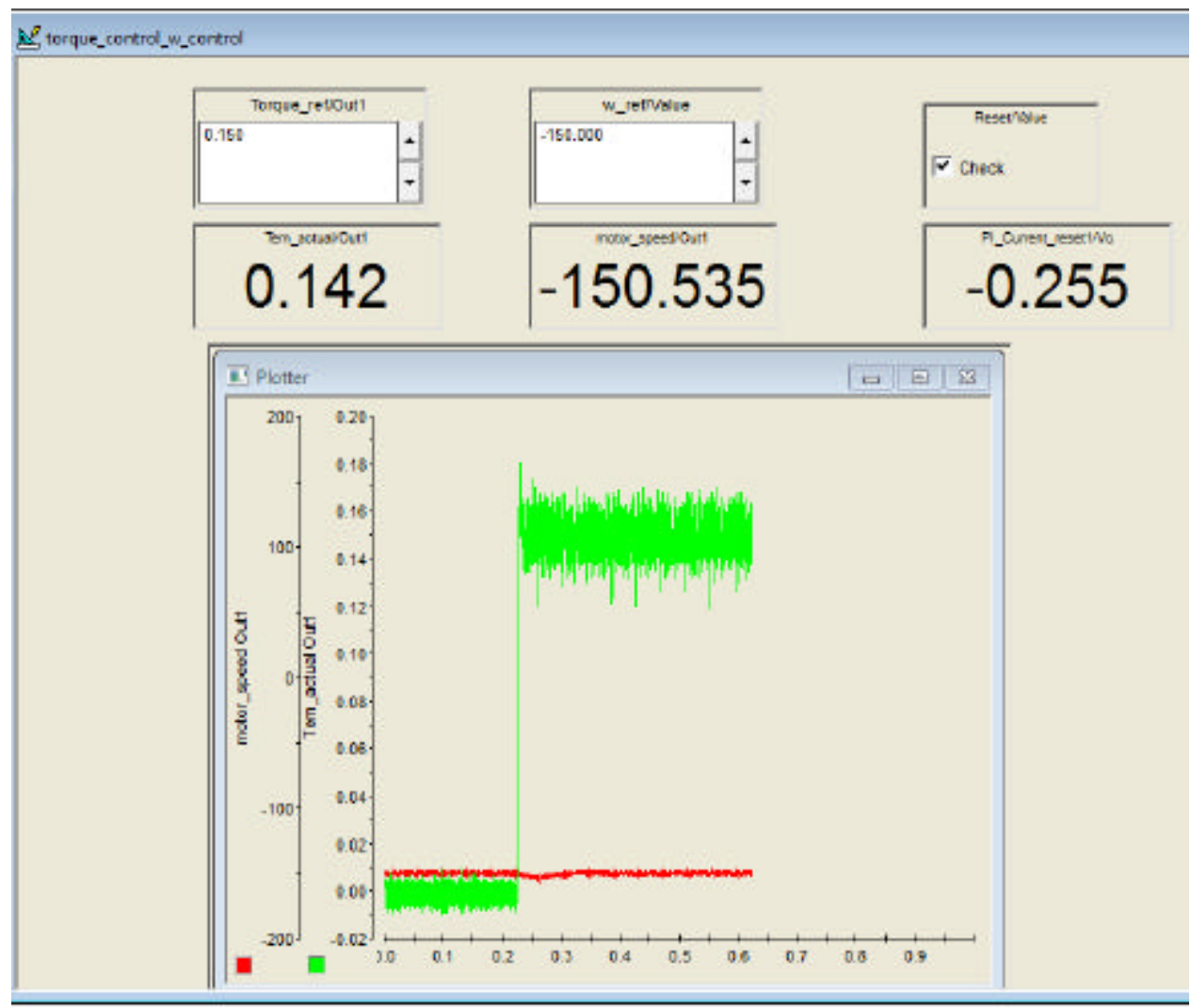

Fig. 7: DSpace control desk result waveform by torque step 0.15

$$
\mathrm{W}_{\mathrm{m}}=\frac{\mathrm{v}_{\mathrm{a}}}{\mathrm{K}_{\mathrm{e}}}=-\frac{-12}{0.0924}=-129.87 \mathrm{rad} / \mathrm{sec}
$$

However, when the motor is loaded, speed can be calculated by the following calculation:

$$
\mathrm{W}_{\mathrm{m}}=\frac{\left[\mathrm{v}_{\mathrm{a}}-\mathrm{I}_{\mathrm{a}}{ }^{*} \mathrm{R}_{\mathrm{a}}\right]}{\mathrm{K}_{\mathrm{e}}}=\frac{[-12-1.623 * 0.6253]}{0.0924}=-140.85 \mathrm{rad} / \mathrm{sec}
$$
loaded:

The net power motor is zero when the motor is not

$$
\mathrm{p}_{\mathrm{e}}=\mathrm{p}_{\mathrm{m}}=0
$$

However, after applying the load:

$$
\mathrm{p}_{\mathrm{e}}=\mathrm{p}_{\mathrm{m}}=\mathrm{w}_{\mathrm{m}} * \mathrm{~T}_{\mathrm{em}}=-140 * 0.15=-21 \mathrm{~W}
$$

\section{CONCLUSION}

In this research, the monitoring and controlling of the FQDCM has been recognized which will be either motor mode or generator mode. The modeling for the constant load is done by calibrating step change in torque up to $0.15 \mathrm{~N}$. m. The speed of the motor goes down because the motor in this case, works without a controller. In the crane torque model, reverse voltage (-12) has been applied with step change in torque. Thus, the speed of the motor goes down, since, it is in the opposite direction with torque. Also, a speed controller is used to maintain the fixed speed even if the torque is varied by increasing the value of the terminal voltage to keep up with increasing torque. Then, the parameters were extracted from the MATLAB code. Finally, the research has been compared with theoretical calculation and it was corresponding to our experimental work accurately.

\section{ACKNOWLEDGEMENTS}

This study is underpinned by the University of Anbar, College of Applied Sciences and Higher Committee of Education in Iraq (HCED) the sponsor governance of the scholarship to study MSC of Electrical Engineering at the university of New Haven. The research has been done in the power electronics and electric derives lab of the University of New Haven. 


\section{REFERENCES}

Ajmera, Y.A. and S.S. Sankeshwari, 2013. Fuzzy fractional order sliding mode controller for DC motor. Intl. J. Adv. Eng. Technol., 6: 1876-1885.

Monje, C.A., Y. Chen, B.M. Vinagre, D. Xue and V. Feliu, 2010. Continuous-Time and Discrete-Time Implementations of Fractional-Order Controllers. In: Fractional-Order Systems and Controls; Fundamentals and Applications, Monje, C.A., Y. Chen, B.M. Vinagre, D. Xue and V. Feliu (Eds.). Springer, London, England, UK., ISBN:978-1-84996-334-3, pp: 191-212.

Moreno, R., 2012a. [Non-Linear Multivariable Control Real-Time Applications]. National University of Engineering, Lima, Peru, ISBN:9786124072185, Pages: 190 (In Spanish).

Moreno, R., 2012b. [Practical and Advanced Process Control]. National University of Engineering, Lima, Peru, ISBN:978-612-4072-22-2, Pages: 322 (In Spanish).
Rojas-Moreno, A., J. Hernandez-Garagatti, O. Pacheco-De La Vega and L. Lopez-Lozano, 2016. FO based-LQR stabilization of the rotary inverted pendulum. Proceedings of the 2016 Chinese Conference on Control and Decision (CCDC), May 28-30, 2016, IEEE, Yinchuan, China, ISBN:978-1-4673-9715-5, pp: 4292-4297.

Ruszewski, A. and A. Sobolewski, 2013. Position control of DC motor using fractional order controller. Arch. Electr. Eng., 62: 505-516.

Singh, S. and A. Kosti, 2015. Comparative study of integer order PI-PD controller and fractional order PI-PD controller of a DC motor for speed and position control. Intl. J. Electr. Electron. Eng. Telecommun., 4: 22-27.

Taha, M.Q. and M.A. Lpizra, 2016. Design a new PWM switching technique in multilevel converters. Proceedings of the Annual Connecticut Conference on Industrial Electronics, Technology and Automation (CT-IETA'16), October 14-15, 2016, EEE, Bridgeport, Connecticut, ISBN:978-1-5090-0800-1, pp: 1-4. 